\title{
COMPARISON OF THE EFFICACY AND SAFETY OF THE SUPINE AND PRONE POSITIONS IN PERCUTANEOUS NEPHROLITHOTOMIES FOR KIDNEY STONES
}

\author{
RIO RAHMADI ${ }^{*}$, NUR RASYID, PONCO BIROWO
}

Department of Urology Universitas Indonesia-Dr. Cipto Mangunkusumo Hospital, Jakarta, Indonesia

Email: riorahmadi77@gmail.com

Received: 12 Dec 2018, Revised and Accepted: 10 Mar 2019

\begin{abstract}
Objective: This study was designed to compare the efficacy and safety of the supine and prone positions in percutaneous nephrolithotomies (PCNLs) used for the treatment of kidney stones in Indonesian patients.

Methods: This was a single-blinded randomized controlled trial of those patients undergoing PCNLs from February to May of 2018 . There were 19 subjects in the supine group and 19 in the prone group for a total of 38 study subjects. The study outcomes that were compared included the operative time, hospital length of stay (LOS), stone-free rate, blood loss, conversion to open surgery, blood transfusion, and complications. These outcomes were evaluated using the Student's $t$ test and the chi-squared test.

Results: There were no significant differences in the patient demographics or stone locations between the two groups. Additionally, the medians of the operative times, LOSs, blood losses, and blood transfusions were not statistically different. There was a higher stone-free rate in the supine group than in the prone group ( $70.0 \%$ vs. $47.4 \%$, respectively, $\mathrm{p}=0.151)$. More subjects were transfused in the supine group (30.0\%) than in the prone group $(15.8 \%)$, but this difference was not statistically significant $(\mathrm{p}=0.292)$. The only complications were infundibular lacerations, which occurred in $20 \%$ of the subjects in the supine group and $15.8 \%$ of the subjects in the prone group $(\mathrm{p}=0.732)$.
\end{abstract}

Conclusion: This study showed that the supine and prone positions for PCNLs had similar efficacy and safety outcomes.

Keywords: Supine, Prone, Percutaneous, Nephrolithotomy, Kidney, Stones

(C) 2019 The Authors. Published by Innovare Academic Sciences Pvt Ltd. This is an open access article under the CC BY license (http://creativecommons. org/licenses/by/4. 0/) DOI: http://dx.doi.org/10.22159/ijap.2019.v11s6.33545

\section{INTRODUCTION}

The percutaneous nephrolithotomy (PCNL) is a popular minimally invasive procedure used to remove kidney stones by accessing the pelvicalyceal system percutaneously [1]. Both the European Association of Urology and the Societe Internationale d'Urologie/International Consultation on Urological Diseases guidelines recommend the PCNL as an alternative treatment for $10-20 \mathrm{~mm}$ kidney stones and the main treatment for kidney stones $>20 \mathrm{~mm}[2,3]$.

The PCNL has undergone many surgical technique modifications, including patient positioning. The most common positions are the prone, supine, flank roll, and modified supine positions, with the prone and supine positions being the most popular over the last few years [4-6]. The prone position is the traditional position, and it has been the most widely used position since the 1970s [7] because it offers easier access to the kidneys with a minimal splanchnic injury risk. However, it does have some disadvantages, such as the risk of ventilatory and circulatory disturbances (particularly in obese patients), as well as the risk of ocular and peripheral nerve injuries; not to mention the fact that it is uncomfortable for the patients $[8,9]$.

Lately, the supine position has been used more commonly, with several studies showing that this position is highly effective and safe Due to its compatibility with regional anesthesia procedures, this position is favorable for patients in whom general anesthesia is contraindicated, including those who are obese and/or who have cardiopulmonary problems [6]. The emergence of the supine position has created debates over which is the better position for the PCNL procedure. Additionally, most previous studies were conducted in Caucasian populations, in whom the demographic and kidney stone characteristics differ from those of the Indonesian population. In Indonesia, several similar studies have been conducted. Some of these are ongoing studies, and some have ended but have yet to be published; however, none of them were conducted using a prospective study design. Therefore, this study is the first prospective study designed to compare the efficacy and safety of the supine versus prone positions in PCNLs for the treatment of kidney stones in a national referral hospital in Indonesia.

\section{MATERIALS AND METHODS}

A single-blinded randomized controlled trial was conducted among patients with kidney stones $<20 \mathrm{~mm}$ and $>10 \mathrm{~mm}$ in diameter that were located in the proximal third of the ureter. These patients underwent PCNLs from February to May of 2018 at the Dr. Cipto Mangunkusumo Hospital in Jakarta, Indonesia. Those subjects with renal anomalies, immunodeficiency disorders, ages of $<10 \mathrm{y}$ old, and who declined to participate were excluded from this research.

The sample size for this study was calculated by assuming a type I error probability of 0.05 and an effect size of 24.07. The two treatments were randomly assigned according to a $1: 1$ ratio using simple randomization. Thus, the sample size for the supine group (group A) was 19 subjects, and there were 19 subjects in the prone group (group B), resulting in a total of 38 study subjects. Prior to undergoing surgery, each subject was blinded to their position group but he/she was well-informed about the overall PCNL procedure itself before giving consent. The urologists were aware of and involved in the planning of the subjects' surgical procedures. Before the study began, institutional review board approval was obtained from the hospital's ethical committee, and the study was registered under protocol number 18-03-0216.

All of the procedures were performed under spinal anesthesia. The patient was prepared in the lithotomy position; then, a rigid $22 \mathrm{Fr}$ cystoscope was inserted to evaluate the bladder and assist with the $5 \mathrm{Fr}$ ureteral catheter insertion. A Foley catheter was also inserted for the ureteral catheter position fixation. The patient was then repositioned to the either the prone or supine position according to his/her group assignment. A retrograde pyelogram was obtained before the surgeon punctured the skin to reach into the pelvicalyceal system. The access tract was dilated using a metal fascial dilator up to $6 \mathrm{Fr}$; then, with a $30 \mathrm{Fr}$ tapered fascial dilator, the inner sheath and Amplatz sheath were positioned to allow the introduction of the nephroscope. The stones were identified and fragmented using the lithotripter, and the fragments were removed using stone forceps. Both C-arm pyelography and the nephroscope were used to look for any residual stone 
fragments. The nephroscope was also used to determine if there were any visible lacerations. Finally, the nephroscope was removed, and an $8 \mathrm{Fr}$ nephrostomy catheter was placed before the wound was stitched closed.

The study outcomes included the operative time, hospital length of stay (LOS), stone-free rate, blood loss, conversion to open surgery, blood transfusion, and presence of complications. The operative time was measured from the insertion of the cystoscope sheath for the bladder evaluation and ureteral catheterization until the completion of the wound stitching. The LOS was defined as the number of days from when the surgery was performed until discharge. A patient was considered to be stone free when no stone $>2 \mathrm{~mm}$ was visible. The complications included any unexpected conditions caused by the surgical procedure that resulted in a delay in the patient's recovery, such as the injury of another organ, massive bleeding, urosepsis, and lacerations. However, in this study, the only complications seen were lacerations.

The operative time was the primary endpoint of the study, and an intention-to-treat analysis was performed. The continuous variables were analyzed using the Student's t test or the Mann-Whitney u test, and the categorical variables were analyzed using the chi-squared test. All of the analyses were performed using IBM SPSS Statistics for Windows version 21.0 (IBM Corp., Armonk, NY, USA).

\section{RESULTS AND DISCUSSION}

A total of 38 subjects were recruited (19 subjects in each group), with no drop outs during the study. The baseline characteristics of both groups, including the sex, age, stone burden, and bilateral surgery status, were comparable between the two groups (supine and prone positions) ( $\mathrm{p}>0.05)$ (table 1$)$.

Table 1: Characteristics of the study subjects

\begin{tabular}{lll}
\hline Characteristic & \multicolumn{1}{l}{ Surgical position } & p value \\
\cline { 2 - 3 } & Supine & Prone \\
\hline Sex, n (\%) & $13(70.0)$ & $16(84.2)$ \\
Male & $6(30.0)$ & $3(15.8)$ \\
Female & $49.9 \pm 9.9$ & $51.3 \pm 11.9$ \\
Age, mean \pm SD & $580.3(132.6-4220.2)$ & $973.7(150.7-3014.4)$ \\
Stone burden, median (min-max) & & 0.703 \\
Bilateral surgery, n (\%) & $4(20.0)$ & $7(36.8)$ \\
Yes & $15(80.0)$ & 0.062 \\
No & 0.243 & $12(63.2)$ \\
\hline
\end{tabular}

SD: standard deviation, the stone locations were also similar between the two groups ( $p>0.05$ ) (table 2). More than half of patients ( $>50 \%$ ) in both groups had staghorn calculi.

Table 2: Renal stone locations of the study participants

\begin{tabular}{llll}
\hline Stone locations, $\mathbf{n}(\%)$ & Surgical position & & p value \\
\cline { 2 - 3 } & Supine & Prone & 0.487 \\
Lower pole & $4(21.1)$ & $1(5.3)$ & \\
Upper pole & $0(0.0)$ & $3(15.8)$ & \\
Renal pelvis & $4(21.1)$ & $1(5.3)$ & \\
Calyx (multiple) & $0(0.0)$ & $13(68.4)$ & \\
Staghorn & $11(57.9)$ & $0(0.0)$ & \\
Diverticula & $0(0.0)$ & $0(0.0)$ & \\
Encrusted stents & $0(0.0)$ & & \\
\hline
\end{tabular}

There was no difference between the medians of the operative times ( 95 vs. $90 \mathrm{~min}$ in the supine and prone groups, respectively, $\mathrm{p}=$ 0.943 ), and the LOS medians were comparable between the two groups ( $5 \mathrm{~d}$ in both groups, $\mathrm{p}=0.749$ ). The postoperative assessment showed a higher stone-free rate in the supine group when compared to the prone group $(70.0 \%$ vs. $47.4 \%, \mathrm{p}=0.151)$. None of the subjects underwent conversions to open surgeries. Statistically, the blood loss medians were similar $150 \mathrm{ml}$ in the supine group and $200 \mathrm{ml}$ in the prone group, $\mathrm{p}=0.621$ ). Although a larger proportion of the subjects was transfused in the supine group $(30.0 \%)$ than in the prone group (15.8\%), the difference was not statistically significant $(p=0.292)$. Additionally, the difference between the medians of the blood transfusion amounts was not statistically different $(300 \mathrm{ml}$ in the supine group and $500 \mathrm{ml}$ in the prone group, $\mathrm{p}=0.083$ ). The only associated complications were infundibular lacerations, which occurred in $20 \%$ of the subjects in the supine group and $15.8 \%$ of the subjects in the prone group $(\mathrm{p}=$ 0.732).

Table 3: Interventional outcomes of the study participants

\begin{tabular}{|c|c|c|c|}
\hline \multirow[t]{2}{*}{ Outcome } & \multicolumn{2}{|c|}{ Surgical position } & \multirow[t]{2}{*}{ p value } \\
\hline & Supine & Prone & \\
\hline Operative time in minutes, median (min-max) & $95(45-155)$ & $90(60-155)$ & 0.943 \\
\hline LOS in days, median (min-max) & $4(2-8)$ & $4(3-8)$ & 0.941 \\
\hline Stone-free rate, $\%$ & 70.0 & 47.4 & 0.151 \\
\hline Residual stones, $\mathrm{n}(\%)$ & & & 0.151 \\
\hline Yes & $6(30.0)$ & $10(52.6)$ & \\
\hline No & $14(70.0)$ & $9(47.4)$ & \\
\hline Conversion to open surgery, $\mathrm{n}(\%)$ & & & - \\
\hline Yes & $0(0.0)$ & $0(0.0)$ & \\
\hline No & $20(100.0)$ & $19(100.0)$ & \\
\hline Blood loss in ml, median (min-max) & $150(10-1500)$ & $200(0-1500)$ & 0.621 \\
\hline Blood transfusion, n (\%) & & & 0.292 \\
\hline Yes & $6(30.0)$ & $3(15.8)$ & \\
\hline No & $14(70.0)$ & $16(84.2)$ & \\
\hline Volume of blood transfused in $\mathrm{ml}$, median (min-max) & $300(200-500)$ & $500(500-500)$ & 0.083 \\
\hline Complications, $\mathrm{n}(\%)$ & & & 0.732 \\
\hline Yes & $4(20.0)$ & $3(15.8)$ & \\
\hline No & $16(80.0)$ & $16(84.2)$ & \\
\hline
\end{tabular}

LOS: hospital length of stay 
In this study, the baseline characteristics of the two groups were comparable, which suggests that the random allocation was successful. There were two surgeons involved in this study; both were senior urologists with experience managing more than 50 kidney stone cases per week for the last twenty years. Therefore, their degree of competence should not have biased the study results.

This study was conducted at a tertiary healthcare facility. With that being said, most of the patients admitted had complex kidney stones and/or rather severe comorbidities. Based on the stone locations, more than half of the subjects in both groups were diagnosed with staghorn calculi. This finding was different from previous studies stating that staghorn calculi were not commonly found [10, 11]. However, this does explain the relatively low stone-free rate in this study.

Contrary to the results of previous studies, there were no significant outcome differences between the supine and prone groups. In terms of the operative time and stone-free rate, Jones et al. [10] and Sohail et al. [11] found that the supine position was superior to the prone position. However, it is worth noting that in both studies the staghorn calculi prevalence was less than $50 \%$. In this present study, the staghorn calculi prevalence was greater than $50 \%$ in both groups. This high prevalence of staghorn calculi might have affected the study outcome, especially in prolonging the operative time and reducing the stone-free rate for both positions.

Another study designed to compare the supine and prone positions for treating staghorn calculi also showed results contrary to those from this study [12]. With regard to the operative time, the supine position was more effective for managing staghorn calculi in the PCNLs; however, in that study, endoscopic combined intrarenal surgeries were performed as ancillary procedures.

This study did have some limitations. For example, the authors did not classify the kidney stone types and body mass indexes of the study subjects. Both variables might have influenced the outcomes of the study.

\section{CONCLUSION}

The results of this study showed that the supine and prone positions exhibited similar efficacy and safety outcomes when they were used for the PCNLs.

\section{ACKNOWLEDGMENT}

This article was presented at The $3^{\text {rd }}$ International Conference and Exhibition on Indonesian Medical Education and Research Institute (ICE on IMERI 2018), Faculty of Medicine, Universitas Indonesia, Jakarta, Indonesia. We thank the 3rd ICE on IMERI Committee who had supported the peer review and manuscript preparation before submitting to the journal. This work was supported by the 2018
HIBAH PITTA Medical Faculty of Indonesia University. We thank the $3^{\text {rd }}$ ICE on IMERI Committee who had supported the peer review and manuscript preparation before submitting to the journal.

\section{AUTHORS CONTRIBUTIONS}

All the author have contributed equally

\section{CONFLICT OF INTERESTS}

Declared none

\section{REFERENCES}

1. Yuan D, Liu Y, Rao H, Chang T, Sun Z, Wang Y, et al. Supine versus prone position in percutaneous nephrolithotomy for kidney calculi: a meta analysis. J Endourol 2016;30:754-63.

2. Pradere B, Doizi S, Protetti S, Brachlow J, Traxer O. Evaluation of guidelines for surgical management of urolithiasis. J Urol 2018;199:1267-71.

3. Ziemba JB, Matlaga BR. Guideline of guidelines: kidney stones. BJU Int 2015;116:184-9.

4. Falahatkar S, Mogghadddam AA, Salehi M, Esmaili F. Complete supine percutaneous nephrolithotripsy comparison with the prone standard technique. J Endourol 2008;22:2513-7.

5. DasGupta R, Patel A. Percutaneous nephrolithotomy: does position matter? prone, supine and variations. Curr Opinion Urol 2013;23:164-8.

6. Patel RM, Okhunov Z, Clayman RV, Landman J. Prone versus supine percutaneous nephrolithotomy: what is your position? Curr Urol Reports 2017;18:26.

7. Mak DK, Smith Y, Buchholz N, El-Husseiny T. What is better in percutaneous nephrolithotomy-prone or supine? A systematic review. Arab J Urol 2016;14:101-7.

8. Yazici CM, Kayhan A, Dogan C. Supine or prone percutaneous nephrolithotomy: do anatomical changes make it worse? Arab J Urol 2018;28:10-6.

9. Ganpule AP, Vijayakumar M, Malpani A, Desai M. Percutaneous nephrolithotomy (PCNL) a critical review. Int J Surgery 2016;36(Pt D):660-4.

10. Jones MN, Ranasinghe W, Cetti R, Newell B, Chu K, Harper M, et al. Modified supine versus prone percutaneous nephrolithotomy: surgical outcome from a tertiary teaching hospital. Investigative Clin Urol 2016;57:268-73.

11. Sohail N, Albodour A, Abdelrahman KM. Percutaneous nephrolithotomy in complete supine flank-free position in comparison to prone position: a single-centre experience. Arab J Urol 2016;15:42-7.

12. Gokce MI, Ibis A, Sanci A, Akinci A, Bagci U, Agaoglu EA, et al. Comparison of supine and prone position for percutaneous nephrolithotomy in treatment of staghorn stones. Urolithiasis 2017;45:603-8. 